\title{
Lack of expression of preproorexin and orexin receptors genes in human normal and prostate cancer cell lines
}

\author{
Marta Szyszka, Lukasz Paschke, Marianna Tyczewska, Marcin Rucinski, \\ Paulina Grabowska, Ludwik K. Malendowicz
}

Department of Histology and Embryology, Poznan University of Medical Sciences, Poznan, Poland

\begin{abstract}
Introduction. Studies on expression of orexins (OXs) and their receptors in human prostate gland and human prostatic cell lines are scanty and their results contradictory. Regarding this, we carefully reinvestigated this problem on human prostatic cell lines.

Material and methods. Expression of preproorexin ( $p p O X)$ (6 primer pairs), and orexin receptors 1 and 2 (OXR1, OXR2) (4 and 2 primer pairs, respectively) was assessed by conventional PCR and QPCR in human normal (PrEC, PrSc, PrSmC) and prostate carcinoma (Du145, LNCaP, and PC3) cell lines. We designed intron spanning primers and also we applied primers from earlier publications and commercially available ones.

Results. With the designed primer pairs, in all studied cell lines we failed to demonstrate expression of $p p O X$, $O X R 1$ and $O X R 2$ genes at the mRNA level, while reaction products were observed in control tissues (human placenta and adrenals). Primers applied in earlier studies did not form amplification products specific for preproorexin or orexin 1 receptor. Some commercially available primers for orexin receptor 1 produced false positive results.

Conclusions. We found no evidence for the presence of preproorexin-orexin receptors system genes' mRNAs in human prostate cell lines. The reported premises for these genes' expression in prostate and prostatic cell lines may have arisen either from the presence of non-prostate cells included in the samples or from faulty PCR settings. (Folia Histochemica et Cytobiologica 2015, Vol. 53, No. 4, 333-341)
\end{abstract}

Key words: preproorexin; orexin receptors; human prostate; PrEC; RT-PCR; PrSc; PrSmC; Du145; LNCaP; PC3

\section{Introduction}

In 1998, two independent groups identified peptides in the rat hypothalamus involved in the stimulation of food intake [1-2]. De Lecea and co-workers [1] defined the proteins as hypocretins (HCRT), while Sakurai group [2] - as orexins (OXs). Orexin-A (OXA) corresponded to hypocretin-1 (HCRT1) and orexin-B (OXB) corresponded to hypocretin-2 (HCRT2). Both OXs are produced during posttrans-

\footnotetext{
Correspondence address: Prof. L.K. Malendowicz, Ph.D. Department of Histology and Embryology Poznan University of Medical Sciences 6 Swiecicki St., 60-781 Poznan tel.: +486185464 44, fax: +48618546440 e-mail: 1km@amp.edu.pl
}

lational modification from common precursor preproorexin (ppOX). They biological action is mediated through two specific $G$ protein-coupled receptors (OXR). Orexin receptor 1 (OXR1) is highly selective for OXA, while orexin receptor 2 (OXR2) has affinity for both OXA and OXB peptides.

Initially OXs and their receptors were identified in the CNS. Subsequently, OXs and OXRs have also been detected in a wide range of organs outside the CNS [3-8]. However, expression of OXs-OXRs system and the mechanism of OXs action in peripheral tissues have not been completely clarified.

OXs and OXRs are also expressed in the male reproductive system and data are available among others for human, cattle, sheep and chicken [9-15]. However, expression of OXs and their receptors in human prostate gland is very controversial. In 2011 
our group demonstrated on both mRNA and protein levels (Western blot and immunocytochemistry) low expression of $O X R 2$ in normal human prostate and elevated expression of this gene in benign prostatic hyperplasia (BPH) but we were unable to demonstrate expression of $p p O X$ and $O X R 1$ in studied samples [16]. However, in 2013 expression of OXA and OXR1 in human prostate and expression of OXR1 in human normal prostate epithelium immortalized cell line (PNT1A) was reported [17]. Recently the same group has demonstrated in human prostate carcinoma (PC) expression of ppOX and OXR1 at the mRNA levels. Moreover, authors found in human androgen-dependent prostate carcinoma cells $\mathrm{LNCaP}$ the presence of OXR1 mRNA, levels of which were elevated upon OXA addition to the culture medium [18]. Because of the discrepancy between these two observations we decided to carefully reinvestigate this problem on human prostatic cell lines.

\section{Material and methods}

Cell culture. The human prostate cell lines: prostate epithelial cell (PrEC), prostate stromal cell $(\mathrm{PrSc})$ and prostate smooth muscle cell ( $\mathrm{PrSmC})$ were purchased from Lonza (Walkersville, MD, USA). Each cell line was grown under specific conditions, including special medium in accordance with the recommendations of the seller. Prostate epithelial cells (PrEC) were grown in the Prostate Epithelial Cell Medium Bulletkit ${ }^{\mathrm{TM}}$ (PrEGM) containing BPE (bovine pituitary extract), hydrocortisone, hEGF, epinephrine, transferrin, insulin, retinoic acid, triiodothyronine, GA-1000 (gentamycin) (Lonza). Prostate stromal cells ( $\mathrm{PrSc}$ ) were grown in the Stromal Cell Medium Bulletkit ${ }^{\mathrm{TM}}$ (SCGM) containing growth supplements: hFGF-B, insulin, FBS, GA-1000 (Lonza). Prostate smooth muscle cells (PrSmC) were grown in the Smooth Muscle Cell Medium Bulletkit ${ }^{\mathrm{TM}}$ (SmGM-2) containing growth supplements: hEGF, insulin, hFGF-B, FBS and GA-1000 (Lonza). Prostate carcinoma cells (Du145, LNCaP, PC3) were purchased from ATCC (American Type Culture Collection, Manassas, Rockville, MD, USA). LNCaP and Du145 cells were grown in RPMI Medium $1640(1 \mathrm{X})$ + GlutaMAX + HEPES (Gibco, Life technologies, Carlsbad, CA, USA). PC-3 cells were grown in $\mathrm{F}-12 \mathrm{~K}$ medium commercially available from ATCC (American Type Culture Collection).

All cell lines were cultured in Falcon flasks in a humidified incubator at $37^{\circ} \mathrm{C}$ and $5 \% \mathrm{CO}_{2}$. After seeding on the first day, the culture medium was replaced with a new one and then changed every second day. All lines were cultured for 3-4 days but $\mathrm{LNCaP}$ cells for 7-8 days.

RNA isolation. Human prostate culture cells were washed two times using PBS, then the total RNA was extracted using
TRI Reagent (Sigma-Aldrich, Poznan, Poland). Total RNA was purified on columns (NucleoSpin Total RNA Isolation, Qiagen GmbH, Hilden, Germany) [19-23]. The amount of total RNA was determined by optical density at $260 \mathrm{~nm}$ and its purity was estimated by $260 / 280 \mathrm{~nm}$ absorption ratio (higher than 1.8) (NanoDrop spectrophotometer, Thermo Scientific, Waltham, MA, USA). Data for positive samples were obtained from tissue homogenates (human placenta for $p p O X$ and human adrenals for $O X R 1$ and $O X R 2$ ). Total RNA was extracted in a tissue homogenizer using also TRI Reagent (Sigma-Aldrich). Total RNA was also purified on columns (NucleoSpin Total RNA Isolation, Qiagen) in the same procedure as for prostate carcinoma cell lines RNA extraction.

Reverse transcription. Reverse transcription was performed using reverse transcriptase from Transcriptor First Strand cDNA Synthesis Kit (Roche) with Oligo(dT) (Roche Diagnostics Corporation, Indianapolis, IN, USA) as primers in the temperature of $55^{\circ} \mathrm{C}$ for $40 \mathrm{~min}$ (Thermocycler UNO II, Biometra, Göttingen, Germany). $1 \mu \mathrm{g}$ of total RNA was used for a single RT reaction. The RTs were carried out in standard final volumes $(20 \mu \mathrm{L})$. After RT each cDNA containing sample was diluted with $100 \mu \mathrm{L}$ of RNase-free water.

QPCR. Primers were designed by Primer 3 software (Whitehead Institute for Biomedical Research, Cambridge, MA, USA) and purchased from the Laboratory of DNA Sequencing and Oligonucleotide Synthesis, Institute of Biochemistry and Biophysics, Polish Academy of Sciences, Warsaw (Table 1).

The primer designed as PPH01112A for human HCRTR1 was purchased from SABiosciences (Qiagen).

QPCR was performed by means of the Lightcycler 2.0 instrument (Roche, 4.05 software version). Using the above mentioned primers, SYBR green detection system was applied. Each of $20 \mu \mathrm{L}$ reaction mixtures contained $4 \mu \mathrm{L}$ template cDNA (standard or control), $0.5 \mu \mathrm{M}$ of every gene-specific primer and a previously determined optimal $\mathrm{MgCl} 2$ concentration ( $3.5 \mu \mathrm{M}$ for one reaction). According to the Roche LightCyclerFastStart DNA Master SYBR Green 1 Kit procedure for QPCR, $1-5 \mu \mathrm{L}$ of the RT reaction product (cDNA) can be used in $20 \mu \mathrm{L}$ or $50 \mu \mathrm{L}$ final reaction volume. LightCyclerFastStart DNA Master SYBR Green I mix program (Roche) was used. The real-time PCR program included 10 min denaturation step to activate the Taq DNA Polymerase, followed by a three-step amplification program: denaturation at $95^{\circ} \mathrm{C}$ for $10 \mathrm{~s}$, annealing at $56^{\circ} \mathrm{C}$ for $5 \mathrm{~s}$, and extension at $72^{\circ} \mathrm{C}$ for $5 \mathrm{~s}$. Assays were run for maximally 45 cycles. Specificity of reaction products was checked by the determination of melting points $\left(0.1^{\circ} \mathrm{C} / \mathrm{s}\right.$ transition rate $)$. To determine the efficiency of target and reference reactions, standard curves for orexin and GAPDH were prepared with products of conventional RT-PCR. These products were 
Table 1. Conventional RT-PCR and QPCR analyses of $p p O X$ - human orexin neuropeptide precursor, $O X R 1$ - human orexin receptor 1 and $O X R 2$ - human orexin receptor 2

\begin{tabular}{|c|c|c|c|c|c|}
\hline $\begin{array}{l}\text { cDNA } \\
\text { (no. of primers) }\end{array}$ & $\begin{array}{c}\text { Genebank } \\
\text { Accession Number }\end{array}$ & Primer & Primer sequence (5'-3') & Position & $\begin{array}{l}\text { PCR product } \\
\text { size (bp) }\end{array}$ \\
\hline$p p O X(1)$ & NM_001524.1 & $\begin{array}{l}\mathrm{S} \\
\mathrm{A}\end{array}$ & $\begin{array}{c}\text { CATCTCCTTTCCCGGCTACC } \\
\text { GCCCAGGAGACCTTTGTGGA }\end{array}$ & $\begin{array}{c}47-66 \\
100-119\end{array}$ & 73 \\
\hline$p p O X(2)$ & NM_001524.1 & $\begin{array}{l}\mathrm{S} \\
\mathrm{A}\end{array}$ & $\begin{array}{l}\text { TTCCTTCCACAAAGGTCTCC } \\
\text { AGCAAGTCTTTTGACGACAGC }\end{array}$ & $\begin{array}{c}95-114 \\
203-223\end{array}$ & 129 \\
\hline$p p O X(3)$ & NM_001524.1 & $\begin{array}{l}\mathrm{S} \\
\mathrm{A}\end{array}$ & $\begin{array}{c}\text { ACAATTGACAGCCTCAAGGTTC } \\
\text { AGCAGCAGTAGCGTCACGG }\end{array}$ & $\begin{array}{c}2-23 \\
122-140\end{array}$ & 139 \\
\hline$p p O X(4)$ & NM_001524.1 & $\begin{array}{l}\mathrm{S} \\
\mathrm{A}\end{array}$ & $\begin{array}{l}\text { TCCACAAAGGTCTCCTGGGC } \\
\text { CAGCTCGTAGAGGCGGCAAG }\end{array}$ & $\begin{array}{l}100-119 \\
224-243\end{array}$ & 144 \\
\hline $\begin{array}{l}\boldsymbol{p p O X}(5) \\
(\text { data from }[17])\end{array}$ & NM_001524.1 & $\begin{array}{l}\mathrm{S} \\
\mathrm{A}\end{array}$ & $\begin{array}{l}\text { CACAATTGACAGCCTCAAGG } \\
\text { AATGGAGACTCGTCTTTATT }\end{array}$ & $\begin{array}{c}1-20 \\
558-577\end{array}$ & 576 \\
\hline OXRI (6) & NM_001525.2 & $\begin{array}{l}\mathrm{S} \\
\mathrm{A}\end{array}$ & $\begin{array}{l}\text { CAACAGGTTCTTGGTGAAG } \\
\text { TCAGCCTCAAACTTCСTTA }\end{array}$ & $\begin{array}{l}177-195 \\
240-258\end{array}$ & 82 \\
\hline OXR1 (7) & NM_001525.2 & $\begin{array}{l}\mathrm{S} \\
\mathrm{A}\end{array}$ & $\begin{array}{l}\text { TGTTCCGCCAAGCCAGTGACC } \\
\text { AGCATCGGCTCTGCAAGGAC }\end{array}$ & $\begin{array}{l}1362-1382 \\
1585-1604 \\
\end{array}$ & 243 \\
\hline $\begin{array}{l}\text { OXRI }(8) \\
\text { (data from [17]) }\end{array}$ & NM_001525.2 & $\begin{array}{l}\mathrm{S} \\
\mathrm{A}\end{array}$ & $\begin{array}{l}\text { TATGTGGCTGTGTTCGTCGT } \\
\text { CCCAGCGTTCATCACAGAC }\end{array}$ & $\begin{array}{c}542-561 \\
986-1004\end{array}$ & 463 \\
\hline OXRI (9) & \multicolumn{5}{|c|}{$\begin{array}{l}\text { Commercially available PPH01112A primers (SABiosciencescompany, Qiagen), } \\
\text { sequences unknown }\end{array}$} \\
\hline OXR2 (10) & NM_001526.3 & S & $\begin{array}{l}\text { CCAATAGTGCTGCGAATCC } \\
\text { AGTTGCTGATTTGAGTGGTC }\end{array}$ & $\begin{array}{l}1379-1397 \\
1536-1555\end{array}$ & 177 \\
\hline OXR2 (11) & NM_001526.3 & S & $\begin{array}{l}\text { GGCTGAAATAAAGCAGATCCG } \\
\text { AGGTAAACCAGGCATACACA }\end{array}$ & $\begin{array}{l}1185-1205 \\
1338-1357\end{array}$ & 173 \\
\hline GAPDH & NM_001289746.1 & $\begin{array}{l}\mathrm{S} \\
\mathrm{A}\end{array}$ & $\begin{array}{c}\text { GAAGGTGAAGGTCGGAGTCA } \\
\text { GACAAGCTTCCCGTTCTCAG }\end{array}$ & $\begin{array}{l}180-199 \\
359-378\end{array}$ & 199 \\
\hline
\end{tabular}

Oligonucleotide sequences for different sense (S) and antisense (A) primers are shown. ppOX primer No. 5 and OXR1 primer No. 8 were used in $[17,18]$. GAPDH (glyceraldehyde-3-phosphate dehydrogenase) was the reference gene

purified on Millipore columns and their concentrations were determined using the spectrophotometric method. PCR samples were mixed with TE-buffer and purified on columns. After spinning, pure product, which was diluted with TE-buffer, remained on the columns.

Standard curves were made for the following primers: GAPDH (human placenta and adrenal gland), OX, OXR1, OXR2. Using the Lightcycler software, we evaluated qPCR efficiency and $\mathrm{R} 2$ by performing a 10 -fold dilution series experiment of the target assays. These data were obtained for selected primers (identified on agarose gel as a positive control) (Table 2). The limit of detection (LOD) was calculated by serial 10 -fold standard curve dilution experiments. The lowest value of dilution given a specific PCR product was considered as LOD (Table 2).

GAPDH was used as a standard for controlling RT-PCR reaction quality as well as the reference gene in prostatic cell lines. The value of $\mathrm{Cp}$ for GAPDH gene expression was between 19-26 cycles (the lowest cycle for PrSMC, the highest for adrenal gland). In all experiments we used primer concentrations suggested by the Roche protocol.

Electrophoresis. QPCR samples were separated in a $2 \%$ agarose gel prepared with GelStar Nucleic Acid Gel Stain

Table 2. Efficiency, R2 (coefficient of correlation obtained for the standard curve) and LOD (limit of detection) for selected primers identified on agarose gel as a positive control (human placenta and adrenal gland)

\begin{tabular}{|l|c|c|c|}
\hline Primers & Efficiency & R2 & LOD $[\mathbf{n g} / \boldsymbol{\mu L}]$ \\
\hline ppOX (1) & 1.877 & 0.998 & $19.0 \times 10^{-8}$ \\
\hline OXR1 (7) & 1.931 & 0.996 & $15.5 \times 10^{-17}$ \\
\hline OXR2 (11) & 1.859 & 0.998 & $17.6 \times 10^{-18}$ \\
\hline GAPDH & 1.860 & 0.980 & $13.8 \times 10^{-10}$ \\
\hline
\end{tabular}


( $\times 10,000$ concentrate in DMSO) (Lonza, Rockland, ME, USA). This is a highly sensitive fluorescent stain for detecting DNA and RNA. To each probe the 6xOrange Loading dye was added (Thermo Scientific). The O'range ruler (50 kb) (Thermo Scientific) was used as a size marker. In this system size differences between products are notable and such products are easy to recognize on $2 \%$ agarose gel.

\section{Results}

The expression analysis of the studied genes was performed using conventional PCR and QPCR. In all studied human prostatic cell lines (LNCaP; Du145; PC3; PrEC; PrSmC and PrSc) we were unable to demonstrate expression of $p p O X$ with primers 1-4 (Table 1), while such products were found in positive control tissue (human placenta) (Figure 1). Of importance is that in all studied prostatic cell lines as well as in human placenta no reaction products were observed with primer No. 5 (Table 1), and in this case analysis of melting temperatures revealed no amplification products (Figure 2A).

Expression of the $O X R 1$ gene was studied with the use of 4 primers (Table 1). In all studied human prostatic cell lines with primers No. 6 and 7 (Table 1) amplifications products were not found; however, they were observed in positive control tissue (human adrenal gland) (Figure 1). On the other hand, with primer No. 8 (Table 1) strips were observed in all studied cell lines and in positive control tissue (Figure 1). However, the size of the obtained products was less than $50 \mathrm{bp}$ and their melting points were very low, approximately $79^{\circ} \mathrm{C}$ (Figure $2 \mathrm{~B}$ ). We also studied expression of $O X R 1$ with commercially available primers (No. 9, Table 1). As shown in Figure 3, reaction products with the size of approximately $100 \mathrm{bp}$ were observed in studied human prostatic cell lines as well as in negative controls (-RT). Thus, the obtained results were false positive. As seen in Figure $2 \mathrm{C}$ and D, melting temperatures of products obtained with these primers were the same $\left(84^{\circ} \mathrm{C}\right)$ in the studied human prostatic cell lines as well as in negative controls (-RT).

Expression of the $O X R 2$ gene was studied with 2 primers (primers 10 and 11, Table 1). In all studied human prostatic cell lines amplifications products were not found, however, they were observed in positive control tissue (human adrenal gland) (Figure 1). In positive control tissue melting temperatures of the obtained products were the same $\left(85.5^{\circ} \mathrm{C}\right)$ (Figure $2 \mathrm{E}$ ).

As it follows from data shown in Table 2, for selected primers (ppOX (1); OXR1 (7); OXR2 (11) and GADPH) efficiencies and R2 values were very high and were within the recommended ranges for

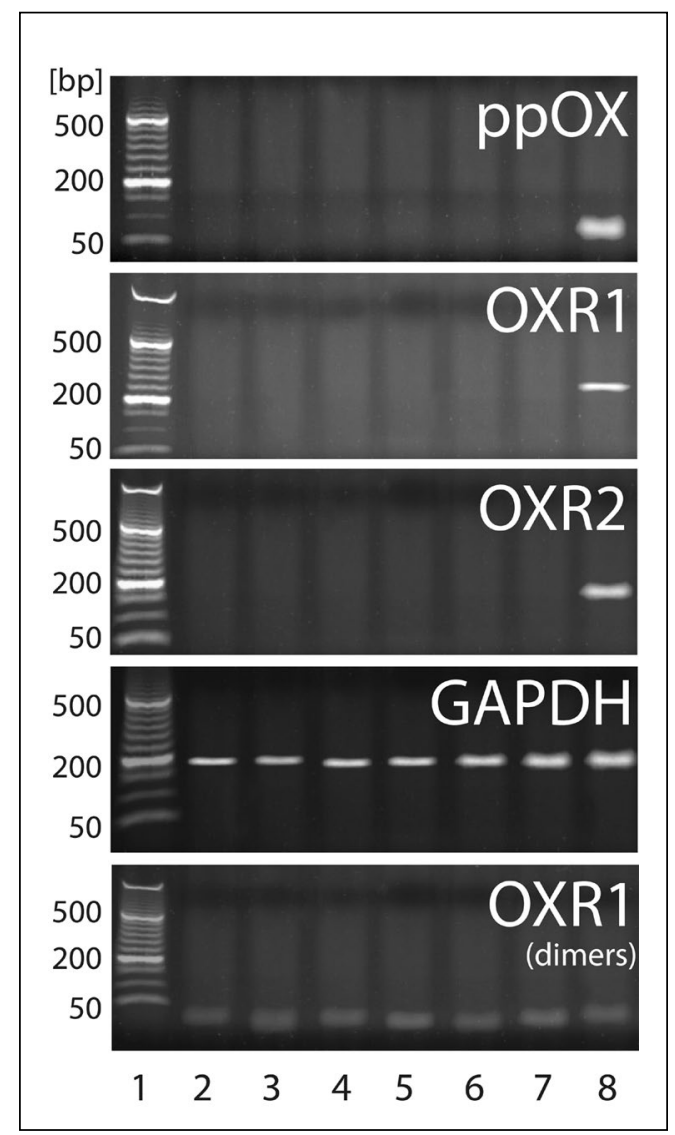

Figure 1. Electrophoretic analysis of RT-PCR products on agarose gel in examined human prostatic cell lines. 1 - marker O'rangeruller (50 kb); 2 - LNCaP line; 3 - Du145 line; 4 - PC3 line; 5 - PrEC line; 6-PrSmC line; 7 - PrSc line; 8 - positive control tissues (for $p p O X$ - human placenta, for $O X R 1$ and $O X R 2$ — human adrenal gland). $p p O X$ - analysis with primers No. 1 from the Table 1; $O X R 1$ - primers No. 7 from the Table 1; OXR2 - primers No. 10 from the Table 1; GAPDH - the reference gene, and $O X R 1$ (dimers) - primers No. 8 from the Table 1 - dimers are visible in each sample, even positive control. Negative controls (-RT of the RNA) are not shown

QPCR assays. As revealed by dilution experiments, the lowest LOD values were obtained for OXR1 (7) and OXR2 (11) primers.

\section{Discussion}

Studies on the expression of OXs and their receptors in human prostate gland and human prostatic cell lines are scanty and their results contradictory. Moreover, most relevant data were obtained by means of immunohistochemistry (IHC); however, many of the currently available antisera can produce nonspecific staining [7]. It should be emphasized, that as it follows from numerous studies, IHC staining is not in itself a proof 

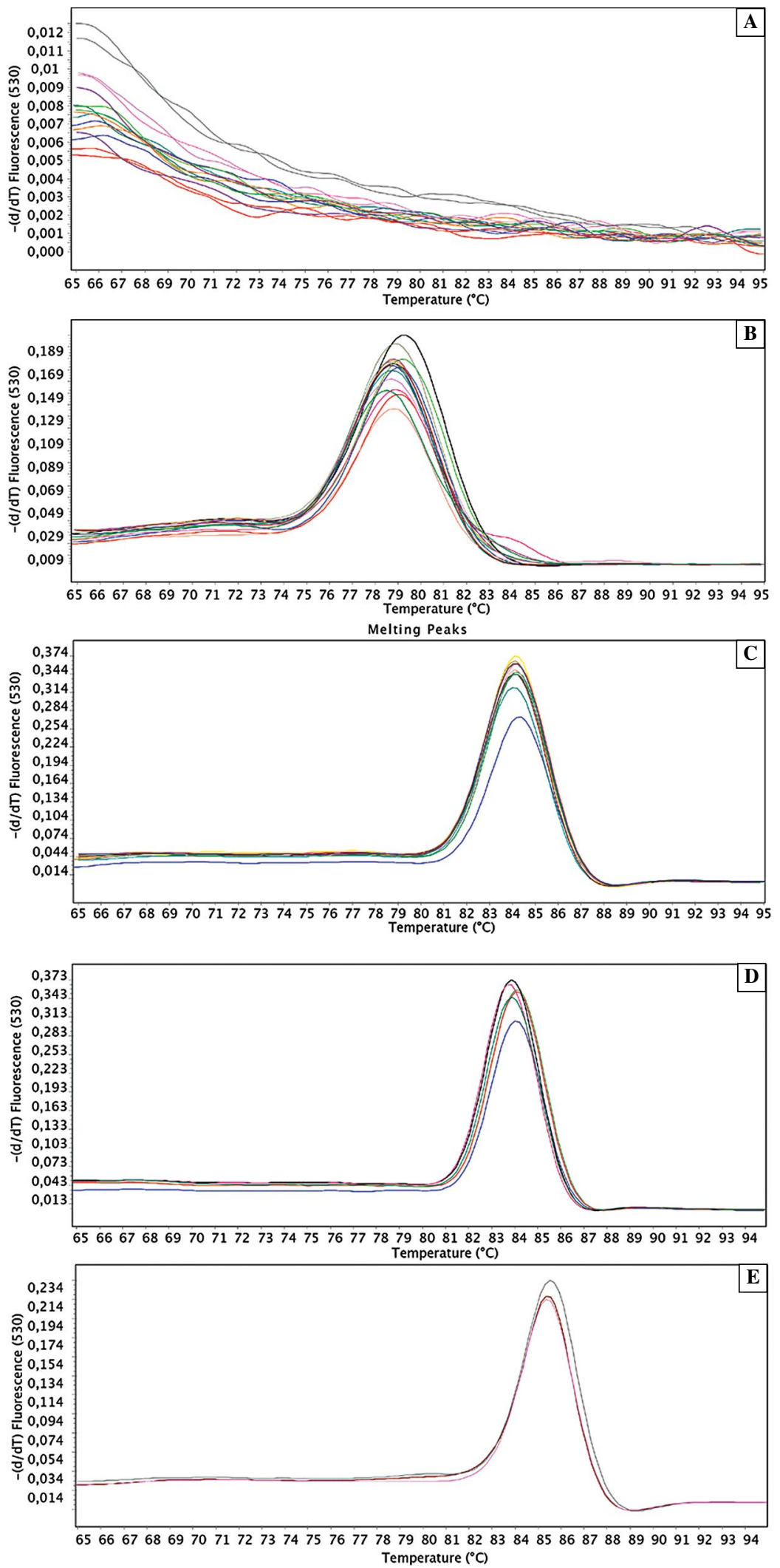

Figure 2. Melting curves (dissociation curves) of QPCR analyses of human $p p O X, O X R 1$ and $O X R 2$. A. $p p O X$ (primers No. 5 from the Table 1) - no amplification products; B. $O X R 1$ (primers No. 8 from the Table 1) - dimers, with very low melting temperature; C. OXR1 in human prostatic cultured cells (primers PPH01112A, SABiosciences - from Figure 3); D. OXR1 negative control -RT (primers PPH01112A SABiosciences - from Figure 3); E. OXR2 in positive control — human adrenal gland (primer No. 10 from the Table 1). All PCR reactions were performed in duplicates 


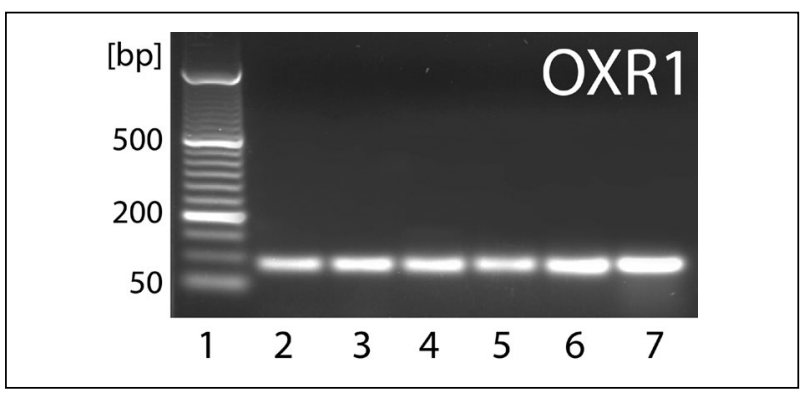

Figure 3. Ethidium bromide-stained $2 \%$ agarose gel showing human prostatic cell lines cDNA (lines 2-5) and -RT negative control (lines 6-7) amplified with commercially available human orexin receptor $1(O X R 1)$ primers (No. 9 in the Table 1, SABiosciences). Note the presence of reaction products with the size of approximately $100 \mathrm{bp}$. Line 1 - marker O'rangeruller (50 kb)

of expression of the studied compound and should be confirmed by more precise methods [24-27].

Earlier reports on the male reproductive system contained no data on expression of the ppOX-OXRs system in the prostate gland [9, 11-14]. To our knowledge, Nakabayashi et al. [28] were the first to report the absence of OXA-like immunoreactivity (LI) in the human prostate. The expression of genes coding for $\mathrm{ppOX}$ in the urethroprostatic complex of cattle was demonstrated by PCR and Western blot, and IHC revealed OXA-LI substances in the exocrine epithelium of the gland [15]. On the other hand, in our earlier QPCR study we were unable to demonstrate expression of $p p O X$ in human normal and hyperplastic prostate [16]. Likewise, in our recent microarray study (Human Obesity RT2 Profiler PCR Array, Qiagen) we were unable to demonstrate expression of ppOX in both normal human prostate gland and benign prostate hyperplasia [29].

Recently, three reports have published data on the presence of OXA-LI in normal human prostate, $\mathrm{BPH}$ and in prostate cancer (PC) $[17,18,30]$. In two of them IHC reaction products for ppOX and OXA were observed in the epithelium of human normal and hyperplastic prostatic glands and the presence of ppOX protein was confirmed by Western blotting. The French group, on the other hand, observed OXA-LI in 'fiber-like' structures of the stroma and no reaction was observed in cancerous foci of PC [30]. Moreover, Valiante et al. [17, 18] demonstrated also expression of $p p O X$ by means of RT-PCR. In light of these discrepancies we performed studies on the expression of $p p O X$ in 6 human prostatic cell lines - LNCaP; Du145; PC3; PrEC; PrSmC and PrSc. Interestingly, with the four carefully designed primer pairs, in all studied cell lines we failed to demonstrate expression of $p p O X$.
In an attempt to solve the above mentioned discrepancies on the expression of $p p O X$ in human prostate and prostatic cell lines, we had analyzed RT-PCR method applied in $[17,18]$. To our surprise, in studies on human prostate glands authors used rat brain as a positive control tissue. As it follows from the analysis of primers, the human $p p O X$ primers are unable to amplify rat ppOX, since there is no $100 \%$ homology between human and rat sequences: the left primer of $p p O X$ has only 8 of 20 nucleotides homology to rat sequence, whereas the right primer -15 of 20 nucleotides (Figure 4A). In our hands these primers failed to give positive results. Moreover, analysis of melting temperatures of these primers revealed no amplification products. Thus, the findings of Valiante et al. $[17,18]$ on the presence of ppOX mRNA in human normal and hyperplastic prostate glands and PC seem to be doubtful. It should be pointed out that in both reports authors applied the same primers, however, the obtained amplicons differed substantially in length (576 bp in [17] and $393 \mathrm{bp}$ in [18]) and such different amplicons were also identified in homogenates of the rat brain.

Only scanty data are available on expression of OXRs in human prostatic cell lines. The expression of OXR1 was detected in human normal prostate epithelium immortalized cells PNT1A by means of the Western blot technique [17]. In subsequent report this group demonstrated also the presence of OXR1 mRNA in LNCaP cell line [18]. However, other authors, identified by means of QPCR, the presence of OXR1 mRNA in Du145 but not LNCaP cell line [30]. It has to be emphasized that induction of a neuroendocrine differentiation resulted in a highly significant increase of OX1R mRNA expression in Du145 cells while no such effect was observed in LNCaP cell line [30].

In the present studies, with 4 different primer pairs we failed to demonstrate expression of both $O X R 1$ and $O X R 2$ in all studied human prostatic cell lines LNCaP; Du145; PC3; PrEC; PrSmC and PrSc, while reaction products were observed in positive control tissue (human adrenal gland). The above reported divergences in the expression of OXRs in prostate and human prostatic cell lines prompted us to analyses the details of QPCR methods, on basis of which positive results have been reported. Like in the case of $p p O X$, in studies of Valiante et al. [18] on human prostate glands and cell lines authors used rat brain as a positive control tissue. Again, analysis of primers for $O X R 1$ shows that the human primers are unable to amplify rat OXR1, since there is no $100 \%$ homology between human and rat sequences - the left primer of $O X R 1$ has only 15 of 20 nucleotides homology to rat 


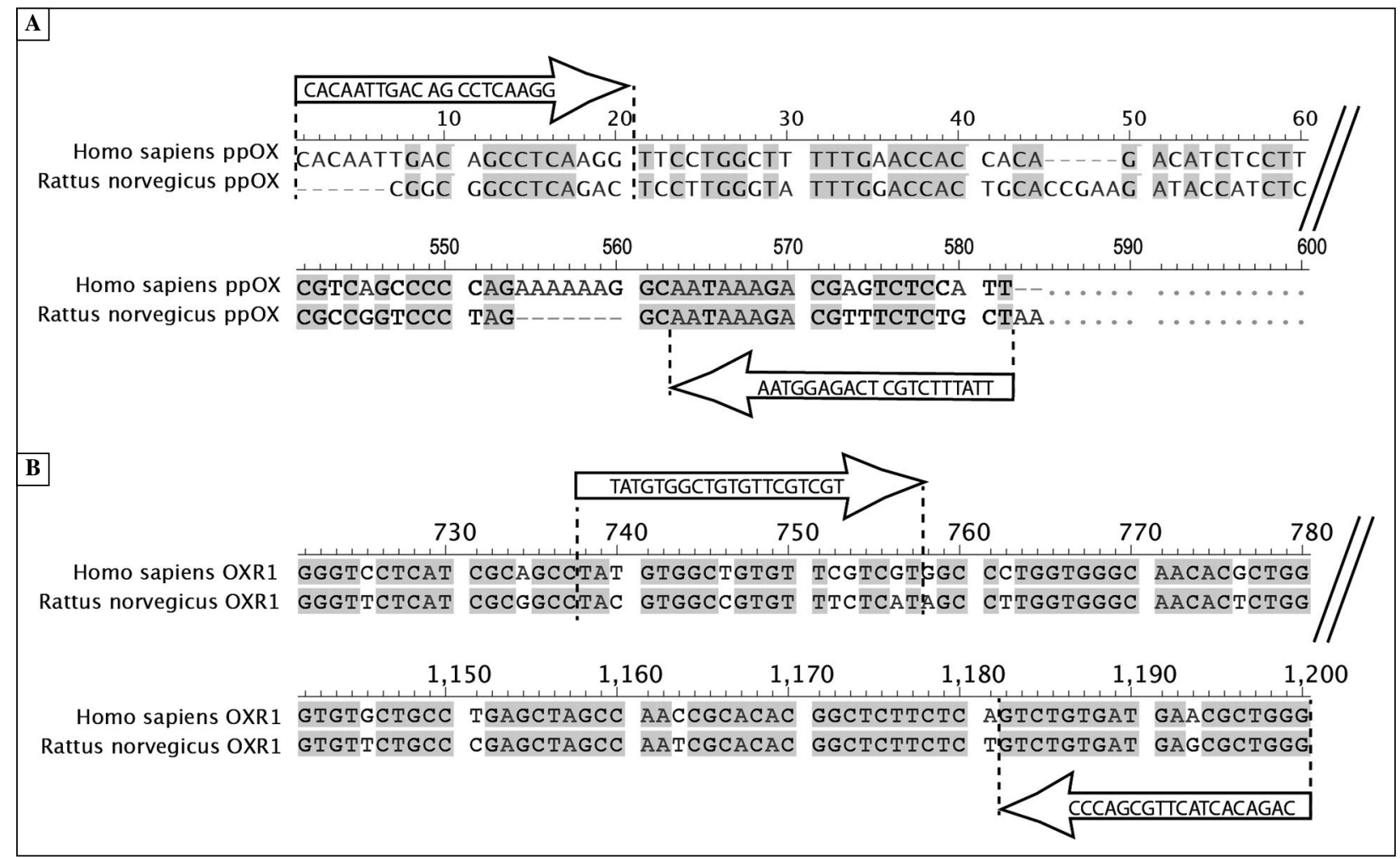

Figure 4. An outline of genes and primers used in [17], shown in arrows, for demonstration of (A) human $p p O X$ (No. 5 in the Table 1) and (B) OXR1 (No. 8 in the Table 1) and their alignment with rat sequences. As seen, binding of primers used for studies of rat tissues are not identical with human cDNA fragments. Homologous nucleotides on a gray background

sequence, whereas the right primer -18 of 19 nucleotides (Figure 4B). In our hands, with these primers reaction products were observed both in all studied prostatic cell lines and positive control tissue. However, the low size of the obtained products $(<50 \mathrm{bp})$ and their very low melting points $\left(\mathrm{ca} 79^{\circ} \mathrm{C}\right)$ suggest that observed products were primer dimers. Thus, reported data on expression of $O X R 1$ in normal human prostate, BPH and PC again are doubtful.

To validate the obtained results in an another manner, we used commercially available primers, which, however, yielded false positive results: with 'PPH01112A for human HCRTR1' primer, reaction products of the size of approximately $100 \mathrm{bp}$ were observed in all studied human prostatic cell lines as well as in negative controls (-RT). Therefore, we are not surprised by results obtained by means of Human Obesity RT2 Profiler PCR Array (SuperArrayBioscience; SABioscience) applied by us in studies on OXR1 expression in normal human prostate and benign prostate hyperplasia [29]. In these studies we demonstrated reaction products for $O X R 1$; however, the primers applied were the same, as purchased for the present study. Furthermore, the size of products (for OXR1) demonstrated with the same primers and shown in both publications $[17,18]$ differed significantly $(463 \mathrm{bp}$ vs. $356 \mathrm{bp}$ ). And again, the same primers give positive reaction with the homogenates of rat brain, which had been used as a control tissue.

In a recent study expression of the OXR1 gene in the human androgen-dependent prostate carcinoma cells $\mathrm{LNCaP}$ was found to be very low (mean Ct value ca 34) and expression of the gene was stimulated by $25 \%$ by the addition of OXA [18]. However, the primers, applied by the authors, span only one exon which does not allow differentiating whether reaction product originates from cDNA or from genomic DNA contaminations. It was reported that samples were digested with DNase [18], but in case of one exon-spanning primers it would be desirable to present also results of negative reactions (-RT).

It has to be mentioned that results of the immunohistochemical studies regarding the presence of OXRs in human prostate and prostatic cell lines are also controversial, mainly due to the various specificity of applied antibodies. Some of them are directed against both OXR1 and OXR2, while others are more specific. In this regard OXR1-LI cells were described in cattle urethroprostatic complex in which expression of OXR1 gene was confirmed by RT-PCR and West- 
ern blot [15]. OXR2-LI, on the other hand was found in epithelial and smooth muscle cells of the stroma as well as in neutrophils in normal and hyperplastic human prostate [16]. In these studies, expression of $O X R 2$, but not $O X R 1$ was confirmed by means of QPCR [16]. Subsequently, OXR1/2-LI was described in the epithelium of normal human prostate as well as in prostate cancer, these data, however, were not confirmed by RT-PCR [31]. OXR1-LI substances were also found in the cytoplasm of epithelial cells of normal and hyperplastic prostates [17]. In their studies expression of $O X R 1$ was also checked by QPCR and authors claim that it is specific reaction, although doubtful primers were used. Recently, OXR1- and OXR2-LI were studied in BPH and PC [30]. OXR1-LI substances in BPH were observed only in scattered cells of few acini while in low and medium grade $\mathrm{PC}$, some cancerous foci contained cells positive for OXR1. In high grade PC adenocarcinomatous formations were intensively stained for OXR1, while OXR2 was only detected in a few cancer cells.

Thus, as it follows from the above discussion, the presence of ppOX and orexin receptors mRNAs in human normal prostate gland, BPH and prostate cancer, as well as in human prostatic cell lines is very controversial. These discrepancies primarily seem to arise from imperfect methodology, in which careful construction of primers and application of numerous control systems, taking into account the species-related differences, is the most important. As we revealed, even commercially available primers, may not be fully reliable, and this notion may hold true also for other types of tissues and cells.

The reported discrepancies on the expression of ppOX-OXRs system in human prostate may also depend on studied materials. OXR1 is reported to be overexpressed in advanced prostate cancer with a neuroendocrine differentiation [30]. Furthermore, acquisition of a neuroendocrine phenotype by the Du145 cells is also associated with an overexpression of $O X 1 R$ [30]. Thus, transformation of prostatic cancerous cells into neuroendocrine cells may profoundly change expression of various genes.

The other source of discrepancies observed in expression of $\mathrm{ppOX}-\mathrm{OXRs}$ system in human prostate may arise from the presence of blood cells present in prostate samples. As reported in the studies on normal and hyperplastic human prostate in which OXR2-LI was found in epithelial and smooth muscle cells of the stroma as well as neutrophils, expression of $O X R 2$, but not $O X R 1$ was confirmed by means of QPCR [16]. Expression of $O X R 2$ in neutrophils was reported in many studies [e.g. 32-34], and it should be noted that in immunology OXR2 is usually described as CD200R1 (http://www.ncbi.nlm.nih.gov/gene/131450).

\section{Conclusions}

In conclusion, our thorough studies revealed no evidence of preproorexin-orexin receptors system gene expression in human prostate cell lines. Available data suggest that all to date found premises for these genes system expression in normal prostate, benign prostatic hyperplasia, prostate cancer and prostatic cell lines may have arisen from either non-prostate cells included in the samples or from faulty PCR settings.

\section{Acknowledgements}

Grant support: the study was supported by grant no. 2011/03/N/NZ3/06095 from the National Science Center, Poland.

\section{References}

1. de Lecea L, Kilduff TS, Peyron C et al. The hypocretins: hypothalamus-specific peptides with neuroexcitatory activity. Proc Nat Acad Sci USA. 1998;95:322-327. PMID: 9419374.

2. Sakurai T, Amemiya A, Ishii M et al. Orexins and orexin receptors: a family of hypothalamic neuropeptides and $G$ protein-coupled receptors that regulate feeding behavior. Cell. 1998;92:573-585. doi: 10.1016/S0092-8674(00)80949-6.

3. Kukkonen JP, Holmqvist T, Ammoun S, Akerman KE. Functions of the orexinergic/hypocretinergic system. Am J Physiol. 2002;283:C1567-C1591. doi: 10.1152/ajpcell.00055.2002.

4. Voisin T, Rouet-Benzineb P, Reuter N, Laburthe M. Orexins and their receptors: structural aspects and role in peripheral tissues. Cell Mol Life Sci. 2003;60:72-87. doi: 10.1007/ s000180300005.

5. Sakurai T. Orexin and Orexin Receptors. In: de Lecea L, Sutcliffe JG, eds. Hypocretins. Integrators of Physiological Signals. Springer: USA; 2005:13-23.

6. Heinonen MV, Purhonen AK, Mäkelä KA, Herzig KH. Functions of orexins in peripheral tissues. Acta Physiol. 2008;192:471-485. doi: 10.1111/j.1748-1716.2008.01836.x.

7. Scammell TE, Winrow CJ. Orexin receptors: pharmacology and therapeutic opportunities. Ann Rev Pharmacol Toxicol. 2011;51:243-266. doi: 10.1146/annurev-pharmtox-010510-100528.

8. Tsunematsu T, Yamanaka A. The role of orexin/hypocretin in the central nervous system and peripheral tissues. Vit Horm. 2012;89:19-33. doi: 10.1016/B978-0-12-394623-2.00002-0.

9. Johren O, Neidert SJ, Kummer M, Dendorfer A, Dominiak P. Prepro-orexin and orexin receptor mRNAs are differentially expressed in peripheral tissues of male and female rats. Endocrinology. 2001;142:3324-3331. doi: 10.1210/endo.142.8.8299.

10. Ohkubo T, Tsukada A, Shamoto K. cDNA cloning of chicken orexin receptor and tissue distribution: sexually dimorphic expression in chicken gonads. J Mol Endocrinol. 2003;31:499_ -508. doi: 10.1677/jme.0.0310499.

11. Karteris E, Chen J, Randeva HS. Expression of human prepro-orexin and signaling characteristics of orexin receptors in the male reproductive system. J Clin Endocrinol Metab. 2004;89:1957-1962. doi: 10.1210/jc.2003-031778. 
12. Barreiro ML, Pineda R, Navarro VM et al. Orexin 1 receptor messenger ribonucleic acid expression and stimulation of testosterone secretion by orexin-A in rat testis. Endocrinology. 2004;145:2297-2306. doi: 10.1210/en.2003-1405.

13. Barreiro ML, Pineda R, Gaytan F et al. Pattern of orexin expression and direct biological actions of orexin-a in rat testis. Endocrinology. 2005;146:5164-5175. doi: 10.1210/en.2005-0455.

14. Zhang S, Blache D, Vercoe PE et al. Expression of orexin receptors in the brain and peripheral tissues of the male sheep. Regul Pept. 2005;124:81-87. doi: 10.1016/j.regpep.2004.07.010.

15. RussoF,Pavone LM, TafuriS, Avallone L,StaianoN, Vittoria A. Expression of orexin A and its receptor 1 in the bovine urethroprostatic complex. Anat Rec. 2008;291:169-174. doi: 10.1002/ar.20641.

16. Malendowicz W, Szyszka M, Ziolkowska A, Rucinski M, Kwias Z. Elevated expression of orexin receptor 2 (HCRTR2) in benign prostatic hyperplasia is accompanied by lowered serum orexin A concentrations. Int J Mol Med. 2011;27:377-383. doi: 10.3892/ijmm.2010.590.

17. Valiante S, Liguori G, Tafuri S et al. Expression of orexin A and its receptor 1 in the human prostate.J Anat. 2013;222:473-480. doi: 10.1111/joa.12030.

18. Valiante S, Liguori G, Tafuri S et al. Expression and potential role of the peptide orexin-A in prostate cancer. Biochem Biophys Res Commun. 2015;464:1290-1296. doi: 10.1016/j. bbrc.2015.07.124.

19. Rucinski M, Albertin G, Spinazzi R, Ziolkowska A, Nussdorfer GG, Malendowicz LK. Cerebellin in the rat adrenal gland: gene expression and effects of CER and [des-Ser1]CER on the secretion and growth of cultured adrenocortical cells. Int J Mol Med. 2005;15:411-415. doi: 10.3892/ijmm.15.3.411.

20. Rucinski M, Andreis PG, Ziolkowska A, Nussdorfer GG, Malendowicz LK. Differential expression and function of beacon in the rat adrenal cortex and medulla. Int J Mol Med. 2005;16:35-40. doi: 10.3892/ijmm.16.1.35.

21. Rucinski M, Ziolkowska A, Szyszka M, Malendowicz LK. Expression of prepro-ghrelin and related receptor genes in the rat adrenal gland and evidences that ghrelin exerts a potent stimulating effect on corticosterone secretion by cultured rat adrenocortical cells. Peptides. 2009;30:1448-1455. doi: 10.1016/j.peptides. 2009.04.016.

22. Ziolkowska A, Rucinski M, Tortorella C, Tyczewska M, Nussdorfer GG, Malendowicz LK. Cultured rat calvarial osteoblast-like cells are provided with orexin type 1 receptors. Int J Mol Med. 2007;20:779-782. doi: 10.3892/ijmm.20.6.779.

23. Tyczewska M, Rucinski M, Trejter M, Ziolkowska A, Szyszka M, Malendowicz LK. Angiogenesis in the course of enucleation-induced adrenal regeneration-expression of selected genes and proteins involved in development of capillaries. Peptides. 2012;38:404-413. doi: 10.1016/j.peptides.2012.09.025.

24. van Leeuwen F. Pitfalls in immunocytochemistry with special reference to the specificity problems in the localization of neuropeptides. Am J Anat. 1986;175:363-377. doi: 10.1002/ aja.1001750218.

25. Ward JM. Controls for immunohistochemistry: is "brown" good enough? Toxicol Pathol. 2004;32:273-274. doi: 10.1080/01926230490457585.

26. True LD. Quality control in molecular immunohistochemistry. Histochem Cell Biol. 2008;130:473-480. doi: 10.1007/ s00418-008-0481-0.

27. Holmseth S, Zhou Y, Follin-Arbelet VV, Lehre KP, Bergles DE, Danbolt NC. Specificity controls for immunocytochemistry the antigen preadsorption test can lead to inaccurate assessment of antibody specificity. J Histochem Cytochem. 2012;60:174-187. doi: 10.1369/0022155411434828.

28. Nakabayashi M, Suzuki T, Takahashi K et al. Orexin-A expression in human peripheral tissues. Mol Cell Endocrinol. 2003;205:43-50. doi: 10.1016/S0303-7207(03)00206-5.

29. Paschke L, Rucinski M, Ziolkowska A et al. ZFP91 A newly described gene potentially involved in prostate pathology. Pathol Oncol Res. 2014;20:453-459. doi: 10.1007/ s12253-013-9716-z.

30. Alexandre $\mathrm{D}$, Hautot $\mathrm{C}$, Mehio $\mathrm{M}$ et al. The orexin type 1 receptor is overexpressed in advanced prostate cancer with a neuroendocrine differentiation, and mediates apoptosis. Eur J Cancer. 2014;50:2126-2133. doi: 10.1016/j. ejca.2014.05.008.

31. Başar MM, Han Ü, Çakan M, Alpcan S, Başar H. Orexin expression in different prostate histopathologic examinations: Can it be a marker for prostate cancer? A preliminary result. Turkish J Urol. 2013;39:78-83. doi: 10.5152/tud.2013.023.

32. Wright GJ, Cherwinski H, Foster-Cuevas M et al. Characterization of the CD200 receptor family in mice and humans and their interactions with CD200.J Immunology. 2003;171:3034-3046. doi: 10.4049/jimmunol.171.6.3034.

33. Steidl U, Bork S, Schaub S et al. Primary human CD34+ hematopoietic stem and progenitor cells express functionally active receptors of neuromediators. Blood. 2004;104:81-88. doi: 10.1182/blood-2004-01-0373.

34. Vernona SD, Nicholson A, Rajeevan $\mathrm{M}$ et al. Correlation of psychoneuroendocrine-immune (PNI) gene expression with symptoms of acute infectious mononucleosis. Brain Res. 2006;1068:1-6. doi: 10.1016/j.brainres.2005.11.013.

Submitted: 3 June, 2015

Accepted after reviews: 21 December, 2015 Available as AoP: 23 December, 2015 